\title{
Nietzsche y la cuestión de la primacía de lo visual en el pensamiento occidental
}

\section{Nietzsche and the issue of the supremacy of the visual in western thinking}

\author{
JOSÉ IGNACIO GALPARSORO
}

Departamento de Filosofía UPV/EHU

Recibido: 07/01/13 Aceptado: 29/05/2013

\begin{abstract}
RESUMEN
Nietzsche ha sido considerado como un autor que defiende los derechos de lo auditivo frente al dominio de lo visual, subrayándose sus reflexiones en torno a la música. El artículo defiende la siguiente tesis: la crítica de Nietzsche al ocularcentrismo no tiene como consecuencia la sustitución de éste por un audiocentrismo excluyente. La crítica nietzscheana a la primacía de lo visual se limita a la concepción de lo visual presentada por la metafísica, mientras que su defensa de lo auditivo va acompañada de una concepción de la visión a la que se podría denominar dionisíaca.
\end{abstract}

\section{PALABRAS CLAVES \\ NIETZSCHE, OCULARCENTRISMO, AUDIOCENTRISMO, MÚSICA, DIONISÍACO}

\section{ABSTRACT}

Nietzsche has been considered to be an author who defends the rights of auditive versus the domination of visual, calling especial attention to his reflections on music. This article defends the thesis that Nietzsche's critique of ocularcentrism does not result in its restrictive replacement by audiocentrism. Nietzsche's criticism to the supremacy of the visual is limited to the conception of the visual presented by metaphysics, while his defense of hearing is accompanied by a conception of the vision which could be called Dionysian.

KEY WORDS

NIETZSCHE, OCULARCENTRISM, AUDIOCENTRISM, MUSIC, DIONYSIAN 


\section{INTRODUCCIÓN: LA TENDENCIA OCULARCENTRISTA}

LA ESTRECHA RELACIÓN EXISTENTE entre visualización y racionalidad, entendida ésta última como ámbito en el que se juega la cuestión de la veracidad, ha sido suficientemente subrayada (Levin 1993, 1-sq.). Así, por ejemplo en el marco del derecho, el testimonio del testigo ocular prevalece sobre el testimonio que es únicamente oído (Jay 2007, 9). También ha sido subrayada la etimología de palabras como «evidencia», que derivan del latín videre (ver) y que se pone de manifiesto en multitud de filósofos que privilegian la transparencia, la claridad, la evidencia o las luces (la ilustración) en la búsqueda de la verdad (Jay 2007, 9). La palabra griega theoría, de la que deriva directamente nuestra palabra «teoría», proviene de theoros (espectador) y está formada por thea (vista) y horao (ver). Es clara, pues, la vinculación del pensamiento especulativo con la experiencia visual. La visión ha parecido, en modo metafórico o literal, el sentido más capacitado para dar cuenta racionalmente de la verdad. Desde Platón a Descartes la visión ha sido considerada como «el más noble de los sentidos» (Jay 1993). Este modelo sugiere que el mundo está completamente abierto a nuestra mirada y está dominado por ella (Shapiro 1998, 364). Hay, pues, una distancia que se abre entre el sujeto y el objeto y esta distancia es la que permitiría una cognición puramente teorética (es decir, espectatorial). En términos heideggerianos, el papel preeminente de la visión constituiría una ayuda decisiva para la constitución de la metafísica de la presencia, comprendida como la noción de que «aquello que es genuinamente real y cognoscible debe ser susceptible de ser completamente manifiesto» (Shapiro 1998, 364). Muchos autores han subrayado que Heidegger habría puesto en tela de juicio el tradicional papel que la visión ha jugado en filosofía. Pero la obra que probablemente ha tratado de manera más exhaustiva la crítica de la tendencia ocularcéntrica de gran parte del pensamiento occidental es la publicada en 1993 por Martin Jay, y traducida al castellano en 2007 con el título Ojos abatidos: la denigración de la visión en el pensamiento francés del siglo XX. Aquí Jay subraya que la crítica al dominio de la visión en el pensamiento occidental ha sido realizada por una gran diversidad de pensadores y artistas franceses del siglo XX, y se ha expresado por medio de una gran variedad de formas que, como señala el propio autor en otro trabajo, «van desde el análisis de la espacialización del tiempo teorizado por Bergson, hasta la evocación del sol cegador y el cuerpo acéfalo por parte de Bataille, desde la descripción «sadomasoquista» que Sartre realiza de «la mirada», hasta la denigración del ego producida por medio del «estadio del espejo» concebido por Lacan; desde la crítica a la vigilancia del panóptico efectuada por Foucault, hasta el ataque de Debord a la sociedad del espectáculo; desde la relación establecida por Barthes entre la fotografía y la 
muerte, hasta la erosión del régimen escópico del cine llevada a cabo por Metz, y desde la indignación de Irigaray ante el privilegio de lo visual en la sociedad patriarcal, hasta la afirmación de Lévinas de que toda Ética es frustrada por una ontología visualmente fundamentada. Incluso un prematuro defensor de lo figural como opuesto a lo discursivo, como fue Lyotard, al final, pudo identificar al postmodernismo, que tanto apadrinó, con la exclusión sublime de lo visual» (Jay 2003, 61-62). A estos nombres podríamos añadir los de Nancy o Derrida en su defensa de otros sentidos diferentes de la visión como el tacto o el oído (Derrida 2000). En definitiva, Jay presenta múltiples ejemplos que desconfían de la visión o que sospechan que ésta no sería, como pretendía la tradición, la herramienta más adecuada para conocer el mundo. ${ }^{1}$

\section{LA ESCUCHA EN NIETZSCHE}

Muchos de los autores que acaban de ser citados tienen un denominador común: se sitúan tras la estela del pensamiento de Nietzsche. Por ello, será de interés considerar el pensamiento a propósito de la visión o de la imagen en este autor que resulta decisivo para la configuración de nuestra actualidad. Algunos estudios (Levin 1993, 4) subrayan la crítica nietzscheana al privilegio de la visión y a los conceptos y métodos basados en la visión en la historia de la filosofía moderna. Ello no significa que Nietzsche habría abandonado por completo las referencias a lo visual, pero sí que su sentido sería totalmente ajeno al descrito por Platón o Descartes. Nietzsche utilizaría las metáforas oculares derivadas de la tradición para subvertir la autoridad del pensamiento ocular. Habría vuelto la lógica del ocularcentrismo contra el ocularcentrismo mismo, alterando así las ambiciones visionarias de la filosofía (Levin 1993, 4).

Otros estudios hacen una interpretación más radical, sosteniendo que Nietzsche habría sustituido el papel protagonista de la visión por el de la escucha (Gallet 2001). Nietzsche habría llevado a cabo una genealogía de aquello que la escucha revela, a saber, un cierto «eco» o una cierta «resonancia». Así, el eco es un sonido tras los sonidos que señala aquello que estos últimos tienden a disimular. El problema es que el eco no es siempre perceptible inmediatamente o no se presenta de manera espontánea: es preciso provocarlo. No basta con acercar el oído a estos sonidos porque no se oye nada si previamente no se ha decidido que intervengan otros elementos agentes que provoquen el eco. Y ésta es la operación que Nietzsche lleva a cabo en un texto central en su obra como el Crepúsculo de los ídolos.

1 Shapiro (2003) puntualiza convenientemente algunas de las afirmaciones de Jay, subrayando que en autores como Foucault o Nietzsche la dimensión de lo visual ocupa un importante lugar en sus respectivas obras. 
Es importante recordar que el título completo de este libro es Crepúsculo de los ídolos o Cómo se filosofa con el martillo. El martillo no ha de ser considerado como una herramienta destructora que se limita a destrozar violentamente el objeto de la crítica, en este caso, los valores de la metafísica y de la moral que han dominado durante milenios en occidente. Si Nietzsche utiliza esta herramienta no es para destruir, sino para crear, como lo deja claramente expuesto en un texto de Así habló Zaratustra («De las tablas viejas y nuevas», § 29) que reproduce al final de Crepúsculo de los ídolos, y que significativamente lleva por título «Habla el martillo». ${ }^{2} \mathrm{El}$ martillo es un instrumento duro y, al mismo tiempo, delicado. Es duro porque le hace falta esta cualidad para enfrentarse a un enemigo resistente. Pero la dureza va acompañada de la precisión y de la delicadeza. El martillo de Nietzsche, más que a una herramienta destructiva, se asemeja al diapasón. La intención de Nietzsche es «auscultar a los ídolos» (Crepúsculo de los ídolos, «Prólogo»). Y estos ídolos a los que se refiere Nietzche no son sino los valores de la metafísica y de la moral. Para llevar a cabo la transvaloración de todos los valores es preciso utilizar el martillo como un «diapasón»: hay que lanzar preguntas a esos ídolos para obtener una respuesta. Y esta respuesta no se ve, sino que se escucha. Los valores de la tradición metafísica eran considerados como sólidamente establecidos. Aparentemente, a primera vista, era así. Pero a nadie se le había ocurrido golpear delicadamente sobre ellos para comprobar qué sonido nos devolvían. Lejos de escuchar un sonido que denota solidez, el eco provocado por el efecto del golpeo del martillo nos devuelve un «sonido a hueco que habla de entrañas llenas de aire» (Crepúsculo de los ídolos, «Prólogo»). Este sonido permite verificar que la pretendidamente sólida construcción de la metafísica no es

2 El texto completo dice así: «“ ¡Por qué tan duro! - dijo en otro tiempo el carbón de cocina al diamante; ¿no somos parientes cercanos?'

-¿Por qué tan blandos? Oh hermanos míos, así os pregunto yo a vosotros: ¿no sois vosotros - mis hermanos?

¿Por qué tan blandos, tan poco resistentes y tan dispuestos a ceder? ¿Por qué hay tanta negación, tanta renegación en vuestro corazón? ¿Y tan poco destino en vuestra mirada?

Y si no queréis ser destinos ni inexorables: ¿cómo podrías algún día - vender conmigo?

Y si vuestra dureza no quiere fulminar y cortar y sajar: ¿cómo podríais algún día - crear conmigo?

Los creadores son duros, en efecto. Y una bienaventuranza tiene que pareceros el imprimir vuestra mano sobre milenios como si fuesen cera, - una bienaventuranza, escribir sobre la voluntad de milenios como sobre bronce, - más duros que el bronce, más nobles que el bronce. Sólo lo totalmente duro es lo más noble de todo.

Esta nueva tabla, oh hermanos míos, coloco yo sobre vosotros: ¡haceos duros! -〉

(F. Nietzsche, Crepúsculo de los ídolos, trad. de A. Sánchez Pascual, Madrid: Alianza Editorial, 1981, p. 139). 
más que una «fábula». Se revela que la pretendida solidez de la construcción sólo provenía del hecho de que se había «creído»durante mucho tiempo que los «ídolos» (i.e. las «verdades» o los «valores») eran, precisamente, sólidos, es decir, incontrovertibles.

La escucha sirve para efectuar la genealogía de la metafísica. Y Nietzsche utiliza también su estrategia genealógica para aplicarla a la audición misma. En un parágrafo de Aurora, titulado significativamente «La noche y la música» (Aurora, § 250), Nietzsche esboza la genealogía del sentido auditivo: «En la noche, y en la semioscuridad de los bosques sombríos y de las cavernas, fue donde el oído, órgano del miedo, pudo desarrollarse tanto como se ha desarrollado, gracias a la manera de vivir de la época de los terrores, es decir, de la más dilatada edad humana que ha existido. Cuando hay claridad, el oído es mucho menos necesario. De ahí el carácter de la música, arte de la noche y de la semioscuridad».

Para tratar el tema que nos ocupa no se trata tanto de subrayar el tono naturalista (i.e., evolucionista) del pasaje o de juzgar si la reconstrucción propuesta por Nietzsche es correcta cuanto de hacer notar la estrecha vinculación presentada entre el oído, la oscuridad (i.e., la ausencia de luz y, por tanto, de visión) y la música. El mundo de la escucha es aquél que el ojo no puede ver. La vista, en cambio, es el órgano de las superficies y de las formas, «el órgano de lo que el día manifiesta y de que aquello que, por eso mismo, ella oculta. El día no es sólo una claridad sobre las cosas, es algo del mundo, uno de sus momentos, aquél en que se resuelve en su superficie, en el que no es más que piel, epidermis. La noche le devuelve a su transparencia y revela al oído una profundidad desapercibida hasta entonces porque era invisible» (Gallet 2001). Para Nietzsche, la música puede penetrar en esta oscuridad. Y ello nos pone sobre la pista de que en este autor el tratamiento de la cuestión de la visión (o de la imagen) pasa por su confrontación con la música (Cf. Picó 2005). Deberemos, pues, abordar la lectura de esos textos del llamado período «juvenil» de Nietzsche, donde la cuestión es abordada con profusión.

\section{Apolo y Dioniso: IMAGEN y MúsiCA}

En su célebre escrito Sobre verdad y mentira en sentido extramoral, Nietzsche considera que el lenguaje -y, en última instancia, la racionalidad-pasa por la mediación de la imagen: el estímulo nervioso se convierte en imagen y ésta en palabra (sonido articulado). Ahora bien, en algunos escritos preparatorios de El nacimiento de la tragedia Nietzsche señala que existe un ámbito que no pasa por la mediación de la imagen; y este ámbito es precisamente la música. La música, afirma Nietzsche, es «bildlos» (literalmente «an-imágica») (KSA 
8, 12[24]). ¿Cómo interpretar esto? ¿Está la música (el elemento dionisíaco) más cerca de la verdad que el lenguaje y, en esta medida, que la imagen? O, más bien, ¿es ésta una tesis schopenhaueriana que Nietzsche abandonó o que, al menos, matizó más tarde? Los intérpretes no se ponen de acuerdo en este punto.

Lo que está más claro es que en el Nacimiento de la tragedia Nietzsche afirma que lo apolíneo está vinculado a la imagen y al concepto (y, en esta medida, a la escultura) y que lo dionisíaco está vinculado a la música. Así, en la primera sección de esta obra, se refiere a lo dionisíaco como «der unbildlichen Kunst der Musik» («el arte no imaginista de la música»), y caracteriza a lo apolíneo como «der Kunst des Bildners» (podríamos traducir «Bildner» por «artista de la imagen» o «artista plástico» -Sánchez Pascual prefiere traducirlo por «el escultor»-, es decir, aquél que proporciona formas: no hay que olvidar que «plástico» viene del griego plastikos, que deriva del verbo plassein, moldear o dar forma (Klein 1997, 105)). La independencia -y, según parece, la superioridad- de la música con respecto a la imagen (y al concepto) es afirmada por Nietzsche en El nacimiento de la tragedia, § 6: «La música misma, en su completa soberanía, no necesita ni de la imagen [Bild] ni del concepto, sino que únicamente los soporta a su lado». Y lo que distingue a la música de la imagen es precisamente el hecho de que significan de maneras radicalmente diferentes: la música, en virtud de su conexión con la voluntad, puede ser el lenguaje de la verdad y el ser, mientras que la imagen está fuera de ellos. El arte dionisíaco preserva la verdad porque permite que la música revele la verdad del ser. Por su parte, el arte apolíneo refleja esta estructura. Pero lo que aquí se preserva no es la verdad, sino la apariencia (Cf. El nacimiento de la tragedia, § 4).

Frente a lo que pudiera pensarse, la teoría nietzscheana de la tragedia no es únicamente una teoría de la música. El elemento dionisíaco ha de verse acompañado por el elemento apolíneo, es decir, visual. La esencia de la tragedia es descrita por Nietzsche como la traducción de la música a imágenes, como lo afirma con claridad en el § 14 de El nacimiento de la tragedia: «La esencia de la tragedia [...] únicamente se puede interpretar como una manifestación e ilustración de estados dionisíacos, como simbolización visual de la música, como el mundo onírico de una embriaguez dionisíaca». La tragedia ática, pues, debe mucho no sólo a Dioniso, sino también a Apolo. En El nacimiento de la tragedia, $\S 21$ se señala claramente que la función de Apolo es «terapéutica», pues gracias a la «energía enorme de la imagen [...] lo apolíneo arrastra al hombre fuera de su autoaniquilación orgiástica y, pasando engañosamente por alto

3 Los Fragmentos Póstumos de Nietzsche son citados a partir de la edición establecida por Colli Montinari. Tras «KSA» se indica el volumen y la numeración del fragmento. Para los textos provenientes de las obras publicadas por Nietzsche, se indica el título de la obra y la numeración o el título del parágrafo correspondiente. 
la universalidad del suceso dionisíaco, le lleva a la ilusión de que él ve una sola imagen del mundo». ${ }^{4}$ Es significativo que, en este contexto, Nietzsche ponga el ejemplo de la obra wagneriana Tristán e Isolda para ilustrar la plasmación del modelo griego en su contemporaneidad. En efecto, la solución propuesta por Nietzsche-Apolo y Dioniso como miembros fraternales de cuya colaboración surge la tragedia-rezuma excesivamente wagnerianismo y shopenhaueranismo e, incluso, dialéctica hegeliana, como el propio Nietzsche reconocerá algunos años después en su «Ensayo de autocrítica».

Poco después de la publicación de El nacimiento de la tragedia (aunque, al entender de algunos intérpretes, el distanciamiento se habría producido incluso antes) Nietzsche rompe claramente amarras con los que fueron sus maestros. La prueba de ello es que el elemento apolíneo desaparecerá casi por completo de sus escritos, permaneciendo tan sólo el elemento dionisíaco que, además, adquirirá un nuevo peso, situándose en el centro de su concepción filosófica, y no circunscribiéndose ya al ámbito de la interpretación del mundo griego. ¿Significa ello que, como sugieren algunos intérpretes a los que nos referíamos al inicio de este capítulo, Nietzsche habría efectuado una sustitución del modelo visual dominante por el repudiado modelo auditivo, simbolizado por el elemento dionisíaco? En otros términos: ¿abogó Nietzsche por la sustitución del ocularcentrismo en favor del audiocentrismo?

\section{CONCLUSIÓN: EL PAPEL DE LA VISIÓN EN NiETZSChE}

Para responder a esta cuestión es preciso abordar previamente el problema de fondo de la posición que Nietzsche defiende tras su crítica a la manera de pensar de la metafísica, basada en oposiciones dicotómicas, que no son sino un reflejo del dualismo. A este respecto, el propio Nietzsche nos proporciona sólidos argumentos para desmentir la interpretación heideggeriana acerca de la presunta inversión nietzscheana del platonismo. En efecto, la estrategia crítica nietzscheana no consiste (como pretende Heidegger (Heidegger 2000, I 148-sq.)) en la mera inversión de los elementos constitutivos del dualismo platónico, colocando en la parte superior de la escala jerárquica aquello que había sido situado por Platón en la parte inferior (lo sensible) y en la parte inferior lo que Platón situó en la superior (lo inteligible), sino en la puesta en tela de juicio del dualismo mismo. Invertir el platonismo habría tenido como consecuencia el mantener en pie el andamiaje de la metafísica. Nietzsche era perfectamente consciente de ello. Por lo cual, y a pesar de alguna declaración explícita presentada en su período juvenil (KSA 7, 7[156]), Nietzsche no consideraba que su filosofía fuera un platonismo invertido. Del mismo modo $-\mathrm{y}$

4 Cf. KSA 7, 3[32]: «La tragedia es el remedio natural contra lo dionisíaco. Hay que vivir: por lo tanto es imposible el puro dionisismo». 
siguiendo formalmente la línea argumentativa de Heidegger-algunos autores ventilan de manera demasiado apresurada la cuestión de la relación entre el ocularcentrismo y el audiocentrismo, presentando una visión dicotómica (i.e., dualista) en la que la visión (el elemento dominante a lo largo de la historia del pensamiento y que por ello habría de ser calificado como «lo malo») habría de ser sustituida por la escucha (el elemento denostado por esa misma historia, al que habría que calificar como «lo bueno»). Según estos autores, Nietzsche representaría un notable ejemplo de tal sustitución. Pero mantener esto sería tanto como afirmar que Nietzsche continúa proponiendo un modelo dicotómico para el tratamiento de la cuestión de la relación entre lo visual y lo auditivo; lo cual, como veremos en seguida, es completamente ajeno a este autor.

Precisamente, Derrida denuncia a esa forma de pensamiento basado en oposiciones dicotómicas, pues continúa situándose en el terreno de la metafísica. Derrida deja, por ejemplo, claro que su crítica al logocentrismo dominante en el pensamiento occidental no pasa por sustituirlo por un grafocentrismo (Derrida 1972, 21). Derrida se limita a seguir en esto el modelo nietzscheano. En efecto, una cosa es defender los derechos de la parte más débil de una pareja de conceptos (en el caso que estamos analizando, de la escucha) frente a la parte dominante (la visión) y otra cosa muy distinta es anular por completo los derechos de la otra parte. En su defensa de la música -o, en general, de lo auditivo- Nietzsche se esfuerza por otorgarle un papel que le había sido negado a lo largo de la historia, tal y como ha sido expuesto más arriba. Pero ello no significa que esté excluyendo a la visión frente a los demás sentidos. Cada sentido juega su papel en el perspectivismo defendido por Nietzsche. Y tan necesarias son para él las metáforas visuales como las auditivas. En esta medida, está para Nietzsche fuera de lugar sustituir el modelo ocularcéntrico por otro audiocéntrico.

Como queda dicho, poco después de El nacimiento de la tragedia Nietzsche abandonará al elemento apolíneo de la pareja de opuestos Apolo-Dioniso. El único elemento que queda es Dioniso, símbolo del devenir y de la aceptación de la vida tal y como se desarrolla en este mundo. El Dioniso del Nietzsche más maduro englobará tanto el elemento musical (en general, lo auditivo) como también el elemento visual, en la medida en que la visión también está bajo la ley del devenir (Shapiro 1993, 126). Si en algunos textos Nietzsche opone la música a la imagen o a la visión es porque la imagen había sido considerada por la metafísica como la forma perfectamente establecida y fijada. La imagen así considerada tiene los atributos del «ser» metafísico; por ello, es preciso denunciar su estatuto. ${ }^{5}$ Shapiro $(1993,139)$ tiene razón cuando subraya que

5 David M. Levin $(1988,69)$ denuncia la identificación que había sido realizada entre la visión y la verdad o el ser al afirmar que cuando miramos fijamente a algo el tiempo suficiente 
en Nietzsche no se trata de valorizar o desvalorizar la visión, sino de repensar la visión. Y de repensarla dentro del mundo del devenir, es decir, del mundo que queda tras haber mostrado que el mundo del «ser» promovido por los metafísicos no es más que una fábula, una historia inventada para escapar del sufrimiento provocado por el carácter inaprensible e imprevisible del mundo.

Repensar la visión pasa por desvincularla de los atributos metafísicos que la tradición ha asociado a ella (estabilidad, permanencia, ausencia de devenir, inmutabilidad) y por vincularla con aquello que representa en grado sumo la fugacidad, a saber: el instante. En alemán, «instante» se dice «Augenblick» (literalmente, el guiño del ojo). Lo cual significa que el instante se expresa mediante una metáfora visual. Y precisamente el instante es el elemento decisivo en la interpretación de ese importante pasaje de Así habló Zaratustra titulado «De la visión y del enigma» en el que es cuestión del eterno retorno. El instante es el elemento central en la reivindicación nietzscheana de la inocencia del devenir, simbolizada por Dioniso. Con su hipótesis del eterno retorno Nietzsche pretende imprimir al instante el sello de la eternidad, devolviéndole el lugar protagonista que le había sido sustraído por la metafísica. Y, para ello, es necesario que el instante se repita por toda la eternidad en la sucesión del flujo infinito del tiempo. La redención no se obtendrá esquivando al devenir mediante la huida a un presunto mundo de esencias, de formas estables, sino en este mundo que es flujo perpetuo. Quien logrará la redención, quien logrará aceptar su vida en este mundo en devenir que no es guiado por ninguna providencia externa a él y que, por tanto, no tiene ninguna finalidad externa a él, será aquél que se atreva a mirar en el abismo y a ver y a aceptar el carácter trágico de la existencia. En el pasaje «De la visión y del enigma», la figura del enano (símbolo del espíritu de la pesadez, es decir, del fardo de esos valores pluriseculares fabricados por la moral y por la metafísica) cuchichea (i.e., habla, dice) algo al oído de Zaratustra. Éste se enfrenta a él mediante la visión abismal, es decir, mediante esa visión dionisíaca que se atreve a ver allí donde no hay fondo o fundamento, es decir, donde no hay un «ser» que garantice la estabilidad. Y ésta es la prueba de que Nietzsche no relega la visión, sino que pretende darle un nuevo impulso, colocándola al lado de otros elementos, como los auditivos. Y es la prueba de que su crítica al ocularcentrismo no tiene como consecuencia la desaparición pura y simple de la visión del terreno de la filosofía. La única visión que es susceptible de crítica es la de las formas inmutables que proponía la metafísica, quien asimilaba la eternidad a la ausencia de instante y, por tanto, a la ausencia de devenir. Por oposición al concepto de visión propuesto por la metafísica, la

«en lugar de una percepción clara y distinta [encontramos] borrosidad y confusión; [...] en lugar de estabilidad y fijeza al fondo de la mirada, encontramos un caos de formas agitadas y cambiantes, como si el objeto del foco se desprendiera violentamente». 
visión dionisíaca reivindicada por Nietzsche sólo está al alcance de quien tiene el coraje de ver el carácter trágico y problemático de la existencia, de quien tiene el coraje de defender la inocencia del devenir, a saber: del superhombre.

\section{REFERENCIAS BIBLIOGRÁFICAS}

DERRIDA, J.1972: Positions. Paris: Les Éditions de Minuit.

—, 2000: Le toucher, Jean-Luc Nancy. Paris: Galilée.

GALLET, B. 2001: «Les labyrinthes de l'écoute : Nietzsche, le monde et la musique» Le Portique, Numéro 8 - 2001, «Nietzsche et le divin», 2001, [En línea], URL : http:// leportique.revues.org/document207.html. Consulta: 1 mayo 2009.

HEIDEGGER, M. 2000: Nietzsche (I y II). Barcelona: Destino.

JAY, M. 1993: Downcast Eyes: The Denigration of Vision in Twentieth-Century French Thought. University of California Press, Berkeley. (trad. cast. Ojos abatidos: la denigración de la visión en el pensamiento francés del siglo XX, Akal, Madrid, 2007).

—, 2003: «La respuesta americana a la crítica francesa al ocularcentrismo», in: Estudios Virtuales, $n^{\circ} 1$, noviembre 2003, pp. 61-82.

—, 2007: «iParresía visual? Foucault y la verdad de la mirada», en Estudios Virtuales, $n^{\circ} 4$, Enero 2007, pp. 8-22.

KLEIN, W. 1997: Nietzsche and the Promise of Philosophy. New York: State University of New York Press.

LEVIN, D. M. 1988: The Opening of Vision. London: Routlege.

LEVIN, D. M. (ed.), 1993: Modernity and the Hegemony of Vision. Berkeley: University of California Press.

NIETZSCHE, F. 1980-sq: Sämtiliche Werke, Kritische Studienausgabe (KSA), Ed. Giorgio Colli \& Mazzino Montinari. Berlin: de Gruyter.

PICÓ SENTELLES, D. 2005: Filosofía de la escucha. El concepto de música en el pensamiento de Friedrich Nietzsche. Crítica, Barcelona.

SHAPIRO, G. 1993: «In the Shadows of Philosophy: Nietzsche and the Question of Vision», en David Michael Levin (ed.): Modernity and the Hegemony of Vision. Berkeley: University of California Press.

—, 1998: «Nietzsche and Visuality», en Michael Kelly: The Encyclopedia of Aesthetics. New York: Oxford University Press, 3: 364-366.

-, 2003: Archaeologies of vision: Foucault and Nietzsche on seeing and saying. Chicago: University of Chicago Press

José Ignacio Galparsoro es profesor titular en el Departamento de Filosofía de la Universidad del País Vasco (UPV/EHU).

Linea de investigación

Estudios en torno a la filosofía contemporánea, fundamentalmente sobre el pensamiento de Nietzsche, así como sobre otros autores como Derrida y Lévi-Strauss o temas como la antropología filosófica y las implicaciones filosóficas de la biología evolucionista. 
Publicaciones recientes

«Sobre el supuesto carácter circular del tiempo en el eterno retorno de Nietzsche» Daímon. Revista Internacional de Filosofia, $\mathrm{n}^{\circ}$ 58, 2012, pp. 81-95

José Ignacio Galparsoro \& Xabier Insausti (eds.), Pensar la Filosofia hoy, Madrid, Plaza y Valdés, 2010.

Dirección electrónica: joseignacio.galparsoro@ehu.es 
